\title{
The Role of Hormones in Financial Markets
}

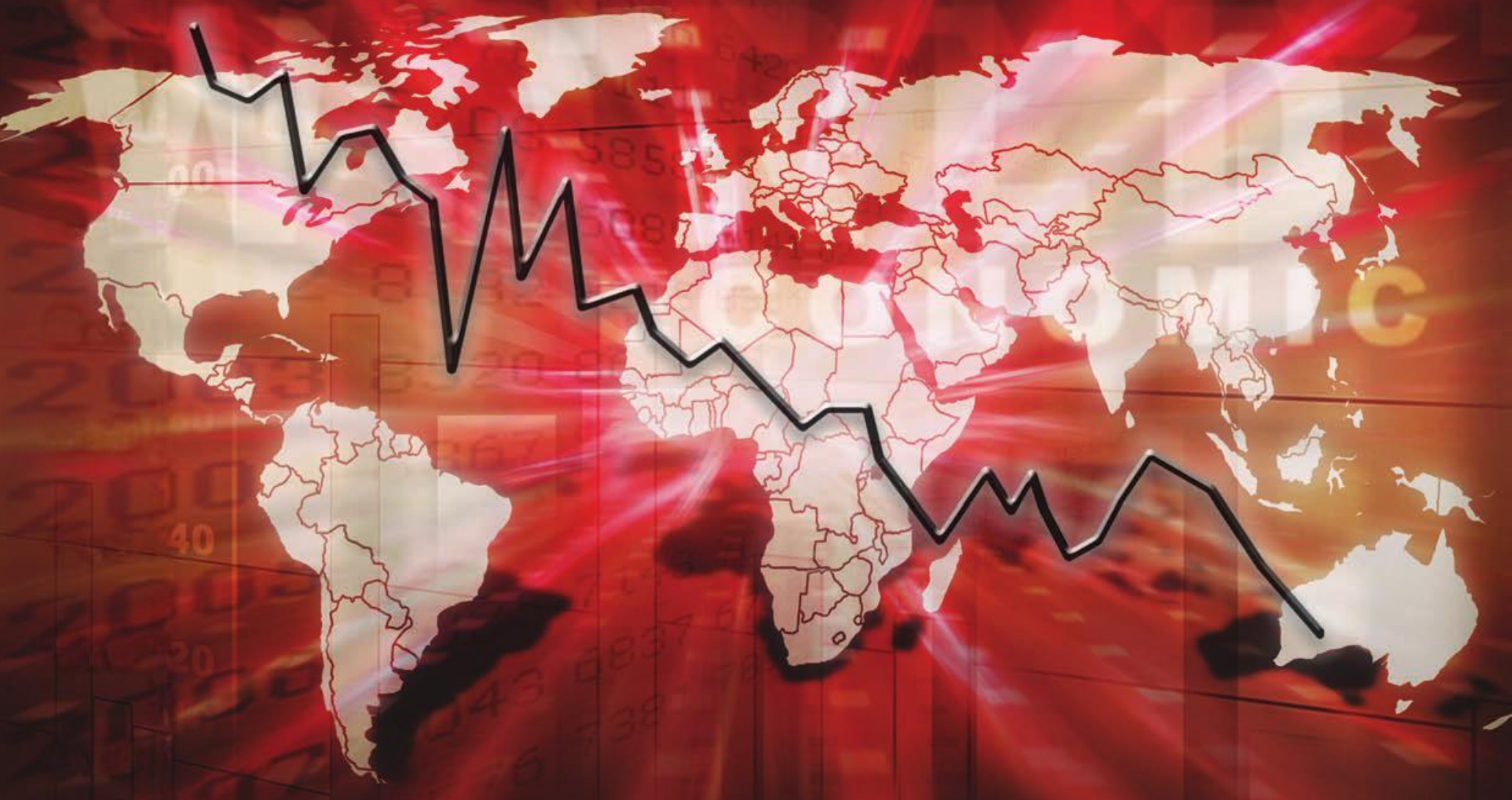

Subir Bose, University of Leicester

Daniel Ladley, University of Leicester

Xin Li, University of Leicester

Working Paper No. 16/01

March 2016 


\title{
The Role of Hormones in Financial Markets
}

\author{
by \\ Subir Bose*, Daniel Ladley ${ }^{\dagger}$, and Xin $\mathrm{Li}^{\ddagger}$
}

March, 2016

\begin{abstract}
Steroid hormones, such as testosterone, have been shown to affect risk preferences in humans with high levels leading to excessive risk-taking. Hormone levels, in turn, are affected by trading outcomes as well as by gender - males are more sensitive to stimuli than females. We investigate the effects of hormones on market behavior and trader performance. An increase in the proportion of female traders does not necessarily make markets less volatile; however, it reduces the occurrence of market crashes. Male traders on average under-perform females, although the best performing individuals are more likely to be male.
\end{abstract}

Keywords: Gender; Hormones; Endogenous risk preference; Market stability; Trader performance

JEL Classification: G10, G02, D02.

\footnotetext{
${ }^{*}$ University of Leicester, Department of Economics, Leicester, UK, LE1 7RH, Email: subir.bose@leicester.ac.uk.

${ }^{\dagger}$ University of Leicester, Department of Economics, Leicester, UK, LE1 7RH, Email: d.ladley@leicester.ac.uk.

${ }^{\ddagger}$ University of Leicester, Department of Economics, Leicester, UK, LE1 7RH, Email: xl107@leicester.ac.uk.
} 


\section{Introduction}

In the past decade, there has been considerable discussions in the media on excessive risk taking in financial markets. In particular, 'reckless' risk taking by traders was, at least partly, blamed for the turmoils and crashes observed in recent years 11 Importantly, it was also argued that traders in the financial markets are 'too male' both in terms of their numbers as well as in the excessively masculine culture of trading floors (e.g., Coates, 2012; Eckel and Fullbrunn, 2015). Consequently, there have been arguments from academics (e.g., Coates et al., 2010), the popular press (e.g., The Guardian, 2012; Time, 2012) and policy makers (e.g., Lagarde, 2013) that a more balanced gender ratio would reduce volatility and help stabilize the markets. Our objective in this paper is to study exactly this issue: to examine how a change in the gender balance of traders affects their performance and the stability of financial markets.

Physiological studies have shown that steroid hormones, for example testosterone, affect risk preference in humans. High levels of testosterone have been shown to be associated with greater, even excessive, amounts of risky behavior (e.g., Apicella et al., 2008; Garbarino et al., 2011), while cortisol has been shown to effect risk preference and to predict market instability (e.g., Cueva et al., 2015). Moreover, there are feedback effects: while hormones affect behavior, outcomes resulting from such behavior in turn may affect hormone levels. In the case of testosterone, levels increase (decrease) in response to success (failure). It has also been demonstrated that there are systematic differences between males and females in this regard: men tend to have higher levels of testosterone as well as experiencing greater fluctuations in their levels than women (e.g., Kivilighan et al., 2005). Gains and losses from financial trading have been shown in laboratory experiments and through the analysis of real traders to lead to greater variance in male hormone levels and risk preferences than is observed in females (e.g., Dreber and Hoffman, 2010).

It is this greater sensitivity to gains and losses that has led to some policy makers,

\footnotetext{
${ }^{1}$ See for example The Guardian, 2011, Time, 2012, 2013
} 
academics and the popular press to call for a reduction in the proportion of male traders in financial markets in order to enhance stability. While it is clear that the behavior of individual male traders is generally more volatile than that of female traders, it is not immediately clear that a decrease in the proportion of male traders would necessarily make markets less volatile. Returns from trading, particularly at short time horizons, are to a large extent affected by trends and dynamics resulting from the trading behavior of others. It is these effects that proponents of the above policy wish to dampen through changing the gender ratio. However, these patterns arise from the interactions of many trading strategies, together with the arrival of information, such that it is not possible to deduce a straightforward relationship between market volatility and the proportions of male and female traders. Our key finding is that an increase in the proportion of female traders makes markets more volatile. However, this finding is with respect to the standard measure of volatility as used in academia and industry; in the popular press the word 'volatility' is often associated with instability. In that regard we find the opposite: a decrease in the proportion of male traders does make the occurrences of extreme events less likely.

To analyze the effects of hormones, we consider a simple trading model in the tradition of De Long et al. (1990b). In our model, informed and positive feedback investors trade over multiple periods in a risky and a riskless asset. Traders have time-varying risk preferences that affect their choice of portfolio compositions. There has been much work examining the form of utility functions (e.g., Kahneman and Tversky, 1982; Spiegel and Subrahmanyam, 1992; Vayanos, 2001) and the degree of risk aversion of individuals (e.g., Longstaff and Wang, 2012; Chabakauri, 2013, Bhamra and Uppal, 2014); these studies, however, assume that choices are made over time based on fixed risk preferences. As argued above, risk preferences not only differ across individuals but also vary over time for a given individual. in response to outcomes from individuals' actions. Traders who make profits become less risk averse, whereas those who make losses become more so. We incorporate this effect in our model by allowing a trader's risk preference parameter to vary in response to the results of 
recent trades. Each trader chooses a portfolio in every period to maximize expected utility from wealth with the optimal choices depending on the trader's risk-preference in their utility function. When the realized return from the chosen portfolio is higher (lower) than the expected return, the risk aversion parameter for the next period decreases (increases). The effect is that success results in an increase in appetite for risk-taking whereas failure lowers it. A crucial issue is not just that risk preferences change but that this variation is systematically different between males and females. To incorporate this we allow the extent of the effect to vary between traders.

The results of our model show that an increase in the proportion of female traders increases the volatility of the asset prices. The presence of a larger fraction of male traders however increases the chances of extreme events. We also find that while female traders have higher average earnings than male traders, the best and the worst performing traders are usually men. This finding indicates the difficulty of changing the gender balance of the trading population in a culture that only rewards star traders.

The rest of the paper is organized as follows. Section 2 briefly reviews the relevant literature on asset pricing methods and the role of hormones in mediating financial behaviors and risk preferences. Section 3 sets out our model incorporating heterogeneous beliefs and time-varying endogenous risk preferences. Section 4 presents details on the analysis and discusses the results. Section 5 concludes.

\section{$2 \quad$ Related Literature}

Our paper is related to the literature concerning physiological effects on economic behavior. Research in this area has examined the links between hormones, financial risk preferences and traders' performance (e.g., Dreber and Hoffman, 2007; Garbarino et al., 2011). Apicella et al. (2008) and Coates and Page (2009) investigate associations between circulatory testosterone levels and financial risk preferences. These studies look at diverse experimental settings 
and find that increases in testosterone lead to greater optimism and risk taking. Moreover, trading results (monetary rewards) of individuals are seen to affect their circulatory hormone levels with high performance linked to higher levels of testosterone (e.g., Apicella et al., 2014). Coates and Herbert (2008) examine the relation between levels of testosterone and trading performance using a sample of male traders. They find that the traders in their sample achieved better results on those days when the trader's testosterone level was higher than the trader's median level over the period. Significantly, when considering the above relationship, male and female traders differed substantially in the variation of hormone levels after winning (losing), affecting their subsequent risk-taking and thus the resulting trading outcomes (e.g., Kivilighan et al., 2005; Dreber and Hoffman, 2010). In general, hormone levels in males seem to be more responsive to winning and losing than in females. This has been argued to be due to the differences in the brain physiology and the early exposures to testosterone (e.g., Cronqvist et al., 2015). While the above papers study behavior of traders, we investigate the effects on the overall market outcomes.

The association between hormones (particularly testosterone) and social behaviors in humans have been examined by a large number of studies in the biology literature. One key finding is the positive relationship between rewards (or punishment) and post-competition hormone levels (Mazur and Booth, 1998; Van Honk et al., 2004; Schultheiss et al., 2005). These studies find that increased testosterone levels are associated with rewards and decreased levels are associated with punishments. See Appendix A for an extended review of this literature.

Our paper is also related to the literature on traders with wrong beliefs (sometimes called irrational traders in the literature). Friedman (1953) argued that such traders cannot influence long-run asset prices because they consistently lose money. This argument was further elaborated on by Muth (1961), Fama (1965) and Lucas (1972), and was used in studies on market efficiency in the presence of noise traders (e.g., Kyle, 1985, De Long et al., 1990a; Campbell and Kyle, 1993; Guo and Ou-Yang, 2015). However, De Long et al. (1990b) 
demonstrate that traders with wrong beliefs may survive under certain market conditions, while Saacke (2002) and Kogan et al. (2006) show that irrational traders can affect prices and persist for long periods in markets. Such effects have also been shown in models such as Brock and Hommes (1998) where the interaction of trading strategies results in persistent and substantial deviations from the fundamental value.

\section{The Model}

The model is constructed in the spirit of De Long et al. (1990b), based on the framework of Brock and Hommes (1998). Consider a market populated by two types of traders, informed and positive feedback (denoted by $h \in\{I, P F\}$ ), where informed traders know the underlying dividend process. The market allows the trade of a risky asset and a risk-free asset. Denote by $p_{t}$ the ex-dividend price per share of the risky asset at time $t$ and $y_{t}$ the stochastic dividend distributed in period $t$. Traders may choose to invest in the risk-free asset with a gross return $R$ or to borrow at the same rate, $R \geq 1$.

Let $w_{t}$ denote the trader's wealth at time $t$ and $Q_{t}$ the number of shares of the risky asset purchased or shorted at time $t$. Wealth of agents evolves according to

$$
w_{t+1}=R w_{t}+\left(p_{t+1}+y_{t+1}-R p_{t}\right) Q_{t}
$$

In period $t$, each type of traders has an expectation of the excess return per share of the risky asset for the coming period, $E_{h, t}\left[p_{t+1}+y_{t+1}-R p_{t}\right]$. Expectations are conditional expectation but for notational simplicity we henceforth refer to them as expectations.

Let $a_{h, t}$ denote the level of risk aversion of agent-type $h$ at time $t$. Traders are myopic mean-variance maximizers who choose the optimal quantity $Q_{h, t}$ to solve

$$
\max _{Q_{h, t}}\left\{E_{h, t}\left[w_{t+1}\right]-\frac{1}{2} a_{h, t} \operatorname{Var}_{h, t}\left[w_{t+1}\right]\right\}
$$


subject to Equation (1). In our study, traders have time varying risk preferences. $E_{h, t}[$.$] and$ $\operatorname{Var}_{h, t}[$.$] are the subjective conditional expectation and conditional variance respectively$ given their beliefs. The conditional variance of wealth $w_{t+1}$ is

$$
\operatorname{Var}_{t}\left[w_{t+1}\right]=Q_{h, t}^{2} \operatorname{Var}\left[p_{t+1}+y_{t+1}-R p_{t}\right]
$$

where the conditional variance of excess returns is assumed to be fixed over time.2 The optimal quantity for trader-type $h$ is the following ${ }^{3}$

$$
Q_{h, t}=\frac{E_{h, t}\left[p_{t+1}+y_{t+1}-R p_{t}\right]}{a_{h, t} \operatorname{Var}}
$$

Let $n_{h}$ represent the proportion of trader-type $h$ in the market $\left(\sum n_{h}=1\right)$ and $Q_{s t}$ the supply of shares per investor. Equilibrium of demand and supply in the market leads to

$$
\sum n_{h} Q_{h, t}=Q_{s t}
$$

When there is only one type of trader in the market, market equilibrium indicates

$$
E_{h, t}\left[p_{t+1}+y_{t+1}\right]-R p_{t}=a_{h, t} \operatorname{Var} Q_{s t}
$$

In the special case of zero supply of outside shares, the required expected return becomes

$$
E_{t}\left[p_{t+1}^{*}+y_{t+1}\right]=R p_{t}^{*}
$$

where $p_{t}^{*}$ is the fundamental value (i.e., present value of future dividends) of the risky asset at time $\mathrm{t}$ and $E_{t}\left[p_{t+1}^{*}+y_{t+1}\right]$ represents the expectation of the fundamental value and dividend conditional on the information set of past prices and dividends..$^{4}$

\footnotetext{
${ }^{2}$ Allowing this figure to vary between trader types does not qualitatively effect the results.

${ }^{3}$ Short selling is permitted $\left(Q_{h, t}<0\right)$.

${ }^{4}$ In the case of positive supply, risk-averse traders require a positive risk premium to hold the risky asset.
} 
In each period, the risky asset distributes a stochastic dividend. The dividend follows an i.i.d. process with mean value $\bar{y}$ and

$$
y_{t}=\bar{y}+\varepsilon_{t}
$$

the noise component $\left\{\varepsilon_{t}\right\}$ is an i.i.d. stochastic process with mean 0 . Innovations of dividends are independent across periods. For this process the best estimate of the future dividend is the mean $\bar{y} 5$

\subsection{Beliefs}

Informed traders estimate the gross return per share according to

$$
E_{I, t}\left[p_{t+1}+y_{t+1}\right]=E_{t}\left[p_{t+1}^{*}+y_{t+1}\right]
$$

where $E_{t}\left[p_{t+1}^{*}+y_{t+1}\right]$ is the common expectation of the fundamental and dividend.

Informed traders believe that the price of the risky asset is determined by its fundamental value, the discounted value of future dividends. They are informed of the underlying dividend processes but not the dividend in any future period.

The second type of trader, positive feedback traders, attempt to profit by exploiting market trends. Positive feedback traders estimate the capital gain by the use of an exponentially weighted moving average of previous returns

$$
E_{P F, t}\left[\frac{p_{t+1}-p_{t}}{p_{t}}\right]=c\left(\frac{p_{t}-p_{t-1}}{p_{t-1}}\right)+(1-c) E_{P F, t-1}\left[\frac{p_{t}-p_{t-1}}{p_{t-1}}\right]
$$

where $c$ is the weight on the most recent percentage observation, $0<c<1$. The expected

\footnotetext{
${ }^{5}$ Our results are robust to alternative dividend processes, see Appendix B.
} 
dividend yield is estimated in the same way,

$$
E_{P F, t}\left[\frac{y_{t+1}}{p_{t}}\right]=g\left(\frac{y_{t}}{p_{t-1}}\right)+(1-g) E_{P F, t-1}\left[\frac{y_{t}}{p_{t-1}}\right], 0<g<1
$$

where $g$ is the weight on the most recent dividend yield. Positive feedback traders rely on only past prices and dividends in making their trading decisions.

Trade therefore happens between those two types of traders when there are disagreements on the asset value and price movements. In every period, the asset price is then determined endogenously by demand and supply.

\subsection{Performance Feedback and Risk Aversion}

In each period, traders calculate their demand based on their levels of risk aversion, conditional expectations and conditional variances of future excess returns per share (as described above). The results of trading are determined by actual excess return per share, denoted by $\Delta r_{t}=p_{t}+y_{t}-R p_{t-1}$. A trader's level of satisfaction given the outcome of trade is calculated

as

$$
Z_{h, t}=\frac{\Delta r_{t}}{E_{h, t-1}\left[p_{t}+y_{t}-R p_{t-1}\right]}-1
$$

We define a positive (negative) outcome as the occasion when the realized profit is greater (lower) than the expected excess return per share, $Z_{h, t}>0\left(Z_{h, t}<0\right) !^{6}$

Within each type of trading strategies (denoted by $j$ ) we consider two sub-groups of traders, namely female traders $(F)$ and male traders $(M)$. Each trader type has a function $F_{h, t}^{j}$, which reflects the change in hormone levels in response to trading outcomes. While the

\footnotetext{
${ }^{6}$ Other forms for the identification of positive and negative outcomes were also considered as the true functional form of humans' responses to trading performance is only known approximately. One such alternative measure is $Z_{h, t}=\frac{\Delta r_{t}}{E_{h, t-1}\left[p_{t}+y_{t}-R p_{t-1}\right]}$, in which a positive outcome happens when traders correctly estimate the sign of the excess return. As long as they make profits, both greater than expected and smaller than expected profits are deemed as positive outcomes. For the case in which agents expect the risky asset to have a positive excess return per share $\left(E_{h, t-1}\left[p_{t}+y_{t}-R p_{t-1}\right]>0\right)$, they enjoy a positive outcome for all $\Delta r_{t}>0$, even if the achieved return per share is positive but lower than expected $\left(0<\Delta r_{t}<E_{h, t-1}\left[p_{t}+y_{t}-R p_{t-1}\right]\right)$. With this alternative measure of positive outcomes, results are qualitatively similar to those with Equation $(12)$.
} 
exact shape of the relationships between outcomes and hormone levels and hormones levels and risk aversion are not known research has demonstrated several key features. Positive (negative) outcomes result in increased (decreased) hormone levels and decreased (increased) risk aversion (Mazur and Booth, 1998, Coates and Herbert, 2008). Further hormone levels are persistent over time and saturate (e.g., Van Honk et al., 2004; Sapienza et al., 2009, Bos et al., 2010). A number of functional forms would describe such a relationship. We adopt one such function $F_{h, t}^{j}\left(Z_{h, t}\right)$ which models the change in hormone levels in response to stimulus and has an increasing and asymptotically bounded form

$$
F_{h, t}^{j}=\kappa^{j} \arctan \left(Z_{h, t}\right), \kappa^{j}>0
$$

where $\kappa^{j}$ measures the degree of hormonal fluctuations of sub-group $j$. The function $F_{h, t}^{j}$ is centered around 0 with range $\left(-\frac{2}{\pi} \kappa^{j}, \frac{2}{\pi} \kappa^{j}\right)$. Traders having positive outcomes $\left(Z_{h, t}>0\right)$ have their levels of hormones rise correspondingly $\left(F_{h, t}^{j}>0\right)$, while negative outcomes $\left(Z_{h, t}<0\right)$ lead to declining levels of hormones $\left(F_{h, t}^{j}<0\right)$. Heterogeneity between female and male traders in our model lies in the degree of hormonal responses to trading outcomes: hormone levels in males being highly responsive to trading outcomes compared to females, $\kappa^{M}>\kappa^{F}$ (see for example Kivilighan et al., 2005; Dreber and Hoffman, 2010). We model informed traders as having fixed risk aversion while positive feedback traders have heterogeneously time-varying risk preferences. This clarifies the mechanism driving our findings.7 However, results are qualitatively similar when we allow for both informed traders and positive feedback traders having heterogeneous time-varying risk preferences.

Based on the changes in hormone levels, trader risk aversion varies according to the following function

$$
a_{h, t}^{j}=a_{h, t-1}^{j}\left(1-F_{h, t}^{j}\right)
$$

\footnotetext{
${ }^{7}$ This separation also captures the intuition that positive feedback traders represent speculators, such as day traders, who often work in the highly male dominated workplaces discussed above. As the informed traders rely more on their information of the fundamental value, they may be considered less responsive to periodical returns and have a fixed level of risk preference over the finite period of trading.
} 
where elevated hormonal levels $\left(F_{h, t}^{j}>0\right)$ decrease traders' levels of risk aversion thereafter $\left.\left(a_{h, t}^{j}<a_{h, t-1}^{j}\right)\right]^{8}$ Traders that achieved good trading outcomes become less risk-averse in the subsequent trading period due to their elevated hormone levels.

Both informed traders and positive feedback traders estimate future price movements and make trading decisions according to their beliefs. The price of the risky asset is determined by the collective demand and supply in the market. Actual excess returns per share from the risky asset come from both price movements and dividends. It is the divergence between actual returns and previous estimations of it that causes fluctuations of hormone levels, affecting agents' risk preferences and therefore their trading decisions. Here we consider two groups within the population of positive feedback traders which respond differently to gains and losses. Given the same trading outcome, male positive feedback traders experience greater elevations (drops) in levels of hormones and thus their risk aversion decreases (increases) more than that of female positive feedback traders.

\section{Results}

In this section we present results from the analysis of the model. The inclusion of endogenous time-varying risk aversion makes the model analytically intractable. As a result the behavior of the model and the effect of the composition of traders on this behaviors are analyzed numerically.

\subsection{Parametrization}

At each time step, the risky asset distributes a stochastic dividend with mean $\bar{y}=1.0$ and a noise component $\varepsilon_{t}$ uniformly distributed on the interval $[-1,1]$. The gross risk-free return is $R=1.01$. The fundamental value of the risky asset at the beginning of the first period is

\footnotetext{
${ }^{8}$ In order to avoid negative risk aversions, in Section 4.1 we choose the parameter values of $\kappa^{j}$ that ensure both $F_{h, t}^{j}<1$ and the risk aversions $a_{h, t}^{j}>0$ across all periods of trading.
} 
$p^{*}=100.9$ The conditional variances of excess returns per share $\operatorname{Var}$, is equal to 1.

In each period, informed traders estimate the fundamental value of the risky asset as the present value of its discounted future dividends. In determining their beliefs about future returns positive feedback traders set the weight on the most recent observation as $c=0.2$, while the weight on most recent dividend yield is $g=0.510$

The degrees of hormonal fluctuations for female traders and male traders, $\kappa^{F}$ and $\kappa^{M}$, are 0.001 and 0.003 respectively. These values of $\kappa^{F}$ and $\kappa^{M}$ mean that traders' levels of risk aversions range between 0 and 12. Results are qualitatively similar for other values of $\kappa^{F}$ and $\kappa^{M}$, as long as $\kappa^{F}<\kappa^{M}$.

The total number of time steps per simulated time series is $T=1000$. The evolution of the market price is path dependent as the trading decisions of each trader in each time step affect market prices, trader's payoffs and thus trading decisions in future periods. For each parameter combination 1000 repetitions were conducted (i.e., runs, denoted by $N$ ), with different random draws from the dividend process. To maintain comparability between parameter combinations, the same 1000 dividend paths are used in each case. The parameters for the numerical analysis are presented in Table 1 .

\subsection{Market Stability}

In this section we show how traders with hormone mediated risk preferences affect overall market stability.

We consider two ratios of male and female positive feedback traders: $95 \%$ male to $5 \%$ female and $50 \%$ male to $50 \%$ female. The composition of $95 \%$ male to $5 \%$ female is close to the observed real world composition of trading floors 4 The composition of $50 \%$ male to $50 \%$ female is representative of the approximate distribution in the general population

\footnotetext{
${ }^{9}$ These parameters satisfy the no-bubble condition $p^{*}=\frac{\bar{y}}{R-1}$. See Brock and Hommes (1998) for a detailed analysis of the no-bubble condition.

${ }^{10}$ We tested different values of $c$ and $g$ and our results are robust for $c<0.7$. For $c \geq 0.7$, the prices become too volatile. The use of the exponentially weighted moving average avoids the highly unstable prices.

${ }^{11}$ This low participation rate of female traders is highlighted by Coates (2012), however, exact figures for this ratio are difficult to obtain.
} 
Table 1: Baseline Parametrization

\begin{tabular}{lll}
\hline Parameter & Meaning & Value \\
\hline $\bar{y}$ & Mean dividend & 1 \\
$\varepsilon_{t}$ & Noise component & $U(-1,1)$ \\
$R$ & Risk-free return & 1.01 \\
$p^{*}$ & Initial fundamental value & 100 \\
$V a r$ & Conditional variance of excess return & 1 \\
$c$ & Weight on most recent percentage price change & 0.2 \\
$g$ & Weight on most recent dividend yield & 0.5 \\
$\kappa^{F}$ & Degree of hormonal fluctuation for female traders & 0.001 \\
$\kappa^{M}$ & Degree of hormonal fluctuation for male traders & 0.003 \\
$T$ & Number of time steps & 1000 \\
$N$ & Number of runs & 1000 \\
\hline
\end{tabular}

and is in line with opinions in the main stream media, which argue this ratio would stabilize markets 12 In the following discussion we refer to the first as the real composition and the second as the balanced composition.

Table 2 reports results examining market stability. The volatility of the risky-asset price under the realistic market composition is significantly lower than under the balanced population. Contrary to popular opinion, increasing the proportion of female traders does not reduce volatility. This is due to the interactions between traders' profits and their hormonal responses. We can view the distribution of results as a range of possible outcomes for a trader entering the market. If a trader is successful, correctly identifying profitable trades, their risk aversion will go down and they will take on larger positions. They will then have a larger effect on market prices and potentially drive trends. If, however, a trader is unsuccessful and loses money, they will become more risk averse and take smaller positions. Price volatility is driven by differences in opinion between traders. In the former scenario traders take larger

\footnotetext{
${ }^{12}$ See for instance "Too much testosterone, too much confidence" in The Guardian, 2012.
} 
Table 2: Moments of Asset Prices

\begin{tabular}{ccccccc}
\hline & \multicolumn{2}{c}{ Male:Female $50: 50$} & & & \multicolumn{2}{c}{ Male:Female $95: 5$} \\
\cline { 2 - 3 } \cline { 5 - 6 } & Value & SD & & Value & SD \\
\hline Term & & & & & \\
Volatility & 0.22572 & $(0.01346)$ & & 0.16937 & $(0.01395)$ \\
Skewness & 0.00712 & $(0.08377)$ & & 0.00687 & $(0.09625)$ \\
Kurtosis & -0.67924 & $(0.11056)$ & & -0.53069 & $(0.15271)$ \\
\hline
\end{tabular}

Note: Results for market with $50 \%$ informed traders to $50 \%$ positive feedback traders. Male:Female is the proportion of male traders to female traders within the group of positive feedback traders. Each simulation was a run for 1000 time steps. Market statistics are averaged over 1000 runs, standard deviations across runs in parenthesis. All values are significantly different at $99 \%$ confidence level. Parameters: $\bar{y}=1$, $\varepsilon_{t} \sim U(-1,1), R=1.01, p^{*}=100, \operatorname{Var}=1, c=0.2, g=0.5, \kappa^{F}=0.001, \kappa^{M}=0.003, T=1000$, $N=1000$.

positions and so drive higher volatility. It is the later scenario, however, that occurs more frequently as, on average, positive feedback traders are outperformed by informed traders. The greater hormonal fluctuations of male traders increase the scale of this effect. As a male trader loses money they become more risk averse than a female trader in the same position and so have a diminished effect on prices. As a result a greater proportion of male traders in the market reduces overall volatility. ${ }^{13}$

While showing a lower average volatility, markets with a realistic composition also show a larger dispersion of volatility than those under a balanced composition. In other words though day to day volatility may be lower these markets are more prone to periods of extreme volatility. Extreme volatility typically occurs when the positive feedback traders correctly pick a trend and make a profit. The profit leads to higher hormone levels and so greater risk taking. As a result the positive feedback traders are able to build and continue a bubble. The larger proportion of male traders exacerbates this effect resulting in larger bubbles and

\footnotetext{
${ }^{13}$ This mechanism still holds if both informed and positive feedback traders are split into male and female. The increase in demand from the male informed traders, pushes prices back towards the fundamental, further reducing volatility.
} 
therefore greater volatility. At some point, however, this bubble will burst as informed traders drive the price back towards the fundamental value. While in the majority of cases the positive feedback traders can not establish trends, when they do that results in higher volatility with more male traders 14

Taken together these results have substantial implications for the debate concerning financial market stability. Increasing the proportion of female traders in the market will have mixed results - an increase in daily volatility coupled with a decreased frequency of extreme events. From a regulatory point of view the second of these concerns will be generally dominant arguing for efforts to rebalance the population of traders. However, our results show that this may be 'politically' difficult. The regulators may face potential criticism as making this change may increase daily volatility. Many observers, including the popular press and financial commentators, use volatility as a proxy for risk, including the risk of catastrophic events. While our results show that the change would indeed be beneficial in terms of reducing the risk of catastrophic events, the regulator may struggle to make this point. In particular the main benefit, the decreased frequency of rare extreme events would, by definition, be hard to observe and therefore use as a justification.

\subsection{Trader Performance}

In this section we examine the relative performance of male traders and female traders. Since gender affects risk aversion, it is natural to examine whether male positive feedback traders outperform female traders or vice versa. Trading outcomes across men and women have been investigated by Barber and Odean (2001) who examine common stock investments of over 35,000 households. By partitioning the data set into accounts traded by men or women, the authors find that performance of women is superior to that of men. The relative performance of traders working for financial firms with respect to their gender, however, has received little attention.

\footnotetext{
${ }^{14}$ Robustness checks show increased dispersions of volatility if the fraction of informed traders is higher than $40 \%\left(n_{I}>0.4\right)$.
} 
Table 3: Normalized Profits

\begin{tabular}{cccc}
\hline & Informed Traders & Male & Female \\
\hline Male:Female 50:50 & & & \\
Mean & 0.197 & -0.203 & -0.192 \\
SD & 1.111 & 1.174 & 1.078 \\
Skewness & 0.960 & -1.172 & -0.826 \\
\hline Male:Female 95:5 & & & \\
Mean & 0.176 & -0.177 & -0.164 \\
SD & 1.129 & 1.138 & 1.036 \\
Skewness & 1.166 & -1.195 & -0.826 \\
\hline
\end{tabular}

Note: Results for market with $50 \%$ informed traders to $50 \%$ positive feedback traders. Male:Female is the proportion of male traders to female traders within the group of positive feedback traders. Normalized profits are volume weighted profits per period. Each simulation was a run for 1000 time steps. Profits are averaged over 1000 runs. All values are significantly different at $99 \%$ confidence level. Parameters: $\bar{y}=1$, $\varepsilon_{t} \sim U(-1,1), R=1.01, p^{*}=100, \operatorname{Var}=1, c=0.2, g=0.5, \kappa^{F}=0.001, \kappa^{M}=0.003, T=1000, N=1000$.

Table 3 reports the periodical profits of informed traders in the market with half informed traders and half positive feedback traders. Two sets of values are presented with the first set representing the balanced male/female composition while the second set corresponds to the real life composition of $95 \%$ male to $5 \%$ female. Informed traders make positive payoffs on average, however, the size of their payoffs is affected by the male/female proportions within the group of positive feedback traders.

The profits earned by informed traders decrease in the proportion of male traders in the market. As explained in Section 4.2 price volatility decreases in the proportion of male positive feedback traders due to increased risk aversions. As the positive feedback traders trade less the price of the risky asset becomes largely driven by informed traders and so becomes closer to the fundamental values. As a result there is little disagreement in the market and so little trade. With fewer positive feedback traders in the market, the total amount of wealth that transfers from positive feedback traders to the informed traders 
decreases. In effect the larger fraction of male traders inadvertently makes the market more informationally efficient.

In order to assess the relative performance of male and female traders, we compare the volume weighted profit per period. This measure describes the average gains or losses on every share traded by the male and female traders. Using this measure removes any across run and time effect on the payoffs due to different trading quantities, leaving only the gender effect. We term this measure normalized profits. The results in Table 3 show that male positive feedback traders achieve both inferior payoffs and larger dispersion of the normalized profits compared to female positive feedback traders. This is the case regardless of the relative proportions of male and female traders within the population. Additionally the distribution of normalized profits for male positive feedback traders is more heavily negatively skewed. The distribution exhibits a much longer tail of losses compared to that of female positive feedback traders. As such male traders have inferior performance on average and more often make the biggest losses.

While male traders under-perform female traders on average their payoffs are also more dispersed than that of females traders. In order to analyze the profits and losses separately, the distributions of payoffs are partitioned by sign. Table 4 presents these statistics. The results for profitable periods reveal an important difference. Male traders earn more than female traders on average when profits are made and their payoffs display significantly higher dispersion and higher positive skewness than those of female traders. The best-performing male traders earn more than the top-ranking female traders. The maximum amount of normalized profits earned by the male positive feedback traders is significantly higher than the maximum amount earned by female positive feedback traders.

Table 4 also shows that among those periods when positive feedback traders make profits, female traders outperform male traders more frequently. However, when male traders make higher profits than females, they outperform female traders by a large amount. This is why the average profit of male traders is greater than that of female traders. Rather than skills 
Table 4: Profits - Positive Outcomes

\begin{tabular}{ccc}
\hline & \multicolumn{2}{c}{ Normalized Profits } \\
\cline { 2 - 3 } & Male & Female \\
\hline Male:Female 50:50 & \\
Mean & 0.629 & 0.627 \\
SD & 0.660 & 0.586 \\
Skewness & 1.790 & 1.285 \\
Outperforming & $42 \%$ & $58 \%$ \\
Positive return periods & 453 & 453 \\
\hline Male:Female 95:5 & & \\
Mean & 0.615 & 0.612 \\
SD & 0.654 & 0.579 \\
Skewness & 1.843 & 1.334 \\
Outperforming & $41 \%$ & $59 \%$ \\
Positive return periods & 459 & 459 \\
\hline
\end{tabular}

Note: Results for market with 50\% informed traders to 50\% positive feedback traders. Profits analyzed here are positive profits generated by male positive feedback traders and female positive feedback traders. Normalized profits are volume weighted profits per period. Male:Female is the proportion of male traders to female traders within the group of positive feedback traders. Outperforming is the fraction of periods that the given gender outperforms the other gender. Each simulation was a run for 1000 time steps. Profits are averaged over 1000 runs. All values are significantly different at $99 \%$ confidence level. Parameters: $\bar{y}=1$, $\varepsilon_{t} \sim U(-1,1), R=1.01, p^{*}=100, \operatorname{Var}=1, c=0.2, g=0.5, \kappa^{F}=0.001, \kappa^{M}=0.003, T=1000, N=1000$. 
it is the excessive risk-taking behavior that makes the best performing traders more likely being male.

These findings have concerning implications for financial firms, regulators and those wishing to change the gender balance in the financial markets. Even though male traders may underperform female traders and make profits less often, reward schemes in financial firms may still select towards large groups of male traders. Financial bonus schemes typically reward the best performers and often lead to large numbers of other traders being fired, potentially even those making small profits. It is important to note that the better performing male traders in these experiments were not more skilled, rather they were lucky. They made larger profits through riding their luck - decreasing their risk aversion, and increasing their investment, in response to profits. The better performing female traders are less susceptible to these effects and so make extreme profits less frequently, even though they also lose money less often. As such hormone effects may explain why financial markets are dominated by men. Trying to rebalance the population of traders to better match that of the population as a whole may require a complete change in how financial firms reward their staff. A movement away from large bonus' for the best performers to a system that better rewards consistent profits.

\subsection{Strategy}

Our analysis of market stability has so far focused on the role of gender; the distribution of informed to positive feedback traders, however, may also have an effect. There is some disagreement with regards to the proportion of traders who use technical rules. It has been estimated to be as high as $90 \%$ by Allen and Taylor (1990) and Taylor and Allen (1992). Lewellen et al. (1980) place the figure between $27 \%$ and $38 \%$ while Hoffmann and Shefrin (2014) suggest $32 \%$. Much of this disagreement seems to stem from the degree of usage of technical approaches with some traders using them as part, rather than all, of their strategy. In this paper we base our analysis on the survey results of Menkhoff and Taylor (2007) who 
Table 5: Moments of Asset Prices

\begin{tabular}{cccccc}
\hline & \multicolumn{2}{c}{ Informed:Positive Feedback $50: 50$} & & \multicolumn{2}{l}{ Informed:Positive Feedback $70: 30$} \\
\cline { 2 - 3 } Term & Value & SD & & Value & SD \\
Volatility & 0.169 & $(0.014)$ & & 0.074 & $(0.006)$ \\
Skewness & 0.007 & $(0.096)$ & & 0.005 & $(0.096)$ \\
\hline
\end{tabular}

Note: Results for market with $95 \%$ to $5 \%$ female traders within the group of positive feedback traders. Informed:Positive Feedback is the proportion of informed traders to positive feedback traders in the market. Each simulation was a run for 1000 time steps. Market statistics are averaged over 1000 runs, standard deviations across runs in parenthesis. All values are significantly different at $99 \%$ confidence level. Parameters: $\bar{y}=1, \varepsilon_{t} \sim U(-1,1), R=1.01, p^{*}=100, \operatorname{Var}=1, c=0.2, g=0.5, \kappa^{F}=0.001, \kappa^{M}=0.003, T=1000$, $N=1000$.

find that in most cases the weight given to technical trading is between $30 \%$ and $70 \%$. In Table 5, we report results for two strategy mixes (the gender mix is held constant at the real composition of $95 \%$ male and $5 \%$ female). The first set represents a market with $50 \%$ informed to $50 \%$ positive feedback traders, and the second for a market with $70 \%$ informed to $30 \%$ positive feedback traders.

The results in Table 5 show that positive feedback traders are capable of destabilizing the market. The larger the proportion of these traders, the higher the volatility of the market price ${ }^{15}$ Price volatility of the risky asset in a market with $70 \%$ informed traders to $30 \%$ positive feedback traders is significantly lower than the scenario with $50 \%$ informed traders to $50 \%$ positive feedback traders. Positive feedback traders add volatility to the market price while informed traders arbitrage misspricings bringing prices closer to the fundamental price. The more informed traders there are in the market, the greater is this effect and the closer is the price of the risky asset to its fundamental value.

This stabilizing effect of informed traders is consistent with the literature on the effect of heterogeneous beliefs in financial markets. Friedman (1953) and Campbell and Kyle

\footnotetext{
${ }^{15}$ This result was tested under different fractions of male and female traders and was found to hold across all compositions.
} 
(1993) show that traders who know better the value of the asset make positive profits and so eventually force the irrational traders out of market. In contrast, De Long et al. (1990b) demonstrate that traders with wrong beliefs are able to increase volatility sufficiently that informed traders are unable to drive them out of the market and so some irrational traders persist in equilibrium. In our model, positive feedback traders lose money in the long-run; however, their trading behaviors impact asset prices while they have wealth available to do so. In the real world, where new traders are continually arriving at the market as they are hired by firms or start brokerage accounts, this implies that these traders will continue to add volatility to market prices.

\section{Conclusion}

Scientists, policy makers and the popular press that have argued that having more female traders would make financial markets more stable. Using an asset pricing model that incorporates a link between risk preferences and trader performance we show that the effects of a more balanced gender composition are more nuanced. An increase in the proportion of female traders may actually increase the volatility of asset prices; however, the chances of extreme events, such as crashes, are reduced. Further, while female traders outperform their male counterparts in terms of average earnings, the best (and the worst) performing traders are likely to be male. In an environment of highly selective performance based evaluation, such as that seen in financial firms, one would expect the population to be increasingly biased towards male traders even though they on average underperform. As such the overly male culture of financial firms may itself be driven by hormones and reward systems. In order to increase the number of female traders it may be necessary to fundamentally change the bonus culture of investing. This study is, to the best of our knowledge, the first to demonstrate the effects of traders' gender mix on financial markets through time-varying trader specific risk preferences. 


\section{Appendix A: Literature on Hormone Testosterone and Social Be- havior}

Over the past 30 years, the potential association between the hormone testosterone and social behavior in humans has been examined in a large number of studies (see for example Mazur and Booth, 1998; Frye et al., 2002). While the studies differ regarding objectives, sample sizes, targeted groups and measurements of testosterone levels, there are some consistent relationships. Brooks and Reddon (1996) find a positive correlation between testosterone levels and violent offenses. Several meta-analyzes Archer, 1991; Book et al., 2001; Archer, 2006) have confirmed a weak positive relationship between testosterone levels and aggression including anger, physical and verbal hostility in males. Other studies (Maras et al., 2003, Rowe et al., 2004; Vermeersch et al., 2008) find evidence of moderate relationships between testosterone and non-aggressive risk taking behaviors in males.

Meanwhile, testosterone levels in females have also been correlated with aggression, violence and other antisocial tendencies (Dabbs et al., 1987; Dabbs and Hargrove, 1997). Apart from aggression and violence, testosterone is also connected to social behaviors such as sensation seeking (Roberti, 2004) and mating-gating (Roney et al., 2003). Buser (2011) explores the biological and hormonal determinants of social preferences by regressing the choices in social preference games on prenatal testosterone exposures (finger length index ratio 2D:4D), and current exposures to progesterone and oxytocin. The study finds a negative effect of prenatal testosterone levels on giving rates in trust, ultimatum and public good games.

Mazur and Booth (1998) propose a reciprocal relationship between testosterone and status. The authors showed that testosterone levels would rise after winning battles and fall after losing. Furthermore, higher testosterone levels could motivate further attempts in gaining status and contests while lower testosterone levels result in quitting to avoid further losses. Schultheiss and Rohde (2002) find a significant testosterone rise in power-motivated contest winners. A number of human studies further demonstrate that increased testosterone levels 
are associated with rewards and decreased testosterone levels are correlated with punishments (Van Honk et al., 2004; Schultheiss et al., 2005). Potential post-competition physiological effects of winning are found in experiments which detected that the likelihood of further wins was followed by elevated testosterone levels (Trainor et al., 2004).

As females have much lower testosterone levels, it is documented that females are likely to be less aggressive than males. Kivilighan et al. (2005) detect the different endocrine responses to competitions and find that testosterone levels in women are less likely to rise after gains compared to males.

\section{Appendix B: Extension with Different Stochastic Processes}

In the description below, we check the robustness of results to different dividend processes.

We first consider a first order autoregressive process, $\operatorname{AR}(1)$,

$$
y_{t}=b+\rho y_{t-1}+\varepsilon_{t}
$$

where the White noise $\left\{\varepsilon_{t}\right\}$ has a mean of zero. This specification addresses the possibility that market information is correlated across periods, and dividends depend linearly on past values. In order to compare with the first stochastic process, the means of dividends are set to be equal, $\frac{b}{1-\rho}=\bar{y}$, with parameters $b=0.639, \rho=0.361$.

Consistent with Section 4.2 , results show that volatility decreases in the male proportion of positive feedback traders, holding the proportion of informed to positive feedback traders fixed (see Table 6). Prices are more stable with an increased proportion of informed traders relative to positive feedback traders (see Table 7). The relative performance of traders are in line with those of Section 4.3 (see Table 8 and Table 91). Informed traders make positive profits both in terms of average periodical profits and cumulative profits over the 1000 periods of trading. Male positive feedback traders perform worse than female positive feedback traders on average, while the group of positive feedback traders makes losses on 
average. Conditional on positive returns, male positive feedback traders earn higher volume weighted profits than females. Different from our main results, the greater dispersion of volatility due to a larger male proportion of positive feedback traders does not persist with AR(1) type dividends. In addition, the level of volatility is significantly higher than that of our baseline economy (with dividend $y_{t}=\bar{y}+\varepsilon_{t}$ ), even though the two sets of stochastic dividends themselves have the same level of dispersion.

The next stochastic dividend process is a two-state Ornstein-Uhlenbeck (OU) process, where the dividend $y_{t}$ is generated from the following stochastic process

$$
y_{t}=e^{-\lambda^{\omega} \Delta t} y_{t-1}+\mu^{\omega}\left(1-e^{-\lambda^{\omega} \Delta t}\right)+\sigma \sqrt{\frac{1-e^{-2 \lambda^{\omega} \Delta t}}{2 \lambda^{\omega}}} \varepsilon_{t}
$$

$\varepsilon_{t}$ is a Wiener process and $\sigma>0$. The state of the economy is represented by $\omega$, where $\omega \in\{$ high, low $\}$, with mean values of dividends $\mu^{\text {high }}>\mu^{\text {low }}$, and $\lambda^{\omega}$ is the speed of mean reversion, $0<\lambda^{\text {high }}<\lambda^{\text {low }}$. The Ornstein-Uhlenbeck process is a modified random walk, in which the process tends to revert back to its long term mean. The mean is higher during expansions and lower in contractions. This two-state process is adopted to capture the boom and bust of an economy. The state switching mechanism is controlled by an unobservable state variable that follows a Markov chain permitting multiple structural changes with unknown timing of state switching. In reality, economic conditions change over time and switching of states could be in line with business cycles or caused by short-term dynamics in the market. The Markov switching model used here captures the exogenous changes to the economy.

Parameters for this model are $\alpha=0.99, \sigma=1, \Delta t=1, \lambda^{\text {high }}=1, \lambda^{\text {low }}=1.3$, $\varepsilon_{t} \sim N(0,1)$. Tables $10,11,12$, and 13 present results on market stability and traders' performance with a narrow distance between boom and bust (state means $\mu^{\text {high }}=1.0576$, $\mu^{\text {low }}=0.95$ ), while Tables $14,15,16$, and 17 describe results for a larger difference in means $\left(\mu^{\text {high }}=1.3452, \mu^{\text {low }}=0.7\right)$. 
With the two-state Ornstein-Uhlenbeck dividend process, results are qualitatively similar to our baseline model. Specifically, informed traders still make positive profits over time. Meanwhile, price volatility decreases in the male proportion of positive feedback traders. The larger the gap between the mean dividends of those two states, the higher the price volatility of the risky asset (volatilities in Table 14 are much higher than the volatility in Table 10). Compared to the results from the baseline model and the AR(1) scenario, results for the two-state OU process show much higher levels of price volatilities and higher profits for the informed traders. Consistent with previous discussions, normalized gains or losses obtained by female positive feedback traders are higher than those of male traders. However, when the gap between the two state means is large, male traders' performance is inferior to females', even conditional on positive earnings being generated.

Our baseline economy and the extensions here all show that price volatility decreases in male proportion of positive feedback traders and informed traders make positive net profits over the trading periods. When traders respond differently to positive and negative outcomes, prices are less volatile in markets with more male traders. Meanwhile, male positive feedback traders do worse than female traders in terms of both average profit and the dispersion of average per share returns. 
Table 6: Moments of Asset Prices

\begin{tabular}{ccccccc}
\hline & \multicolumn{2}{c}{ Male:Female $50: 50$} & & \multicolumn{2}{c}{ Male:Female $95: 5$} \\
\cline { 2 - 3 } \cline { 5 - 6 } & Value & SD & & Value & SD \\
\hline Term & & & & & \\
Volatility & 0.623 & $(0.030)$ & & 0.550 & $(0.029)$ \\
Skewness & 0.007 & $(0.122)$ & & 0.004 & $(0.124)$ \\
Kurtosis & 0.007 & $(0.238)$ & & 0.028 & $(0.245)$ \\
\hline
\end{tabular}

Note: Results for market with $50 \%$ informed traders to $50 \%$ positive feedback traders with AR(1) dividend process. Male:Female is the proportion of male traders to female traders within the group of positive feedback traders. Each simulation was a run for 1000 time steps. Market statistics are averaged over 1000 runs, standard deviations across runs in parenthesis. All values are significantly different at $99 \%$ confidence level. Parameters: $b=0.639, \rho=0.361, \varepsilon_{t} \sim N(0,1), R=1.01, p^{*}=100, \operatorname{Var}=1, c=0.2, g=0.5$, $\kappa^{F}=0.001, \kappa^{M}=0.003, T=1000, N=1000$.

Table 7: Moments of Asset Prices

\begin{tabular}{|c|c|c|c|c|}
\hline & \multicolumn{2}{|c|}{ Informed:Positive Feedback $50: 50$} & \multicolumn{2}{|c|}{ Informed:Positive Feedback $70: 30$} \\
\hline & Value & $\mathrm{SD}$ & Value & $\mathrm{SD}$ \\
\hline \multicolumn{5}{|l|}{ Term } \\
\hline Volatility & 0.550 & $(0.029)$ & 0.425 & $(0.019)$ \\
\hline Skewness & 0.004 & $(0.124)$ & -0.001 & $(0.116)$ \\
\hline
\end{tabular}

Note: Results for market with $95 \%$ to $5 \%$ female traders within the group of positive feedback traders with AR(1) dividend process. Informed:Positive Feedback is the proportion of informed traders to positive feedback traders in the market. Each simulation was a run for 1000 time steps. Market statistics are averaged over 1000 runs, standard deviations across runs in parenthesis. All values are significantly different at $99 \%$ confidence level. Parameters: $b=0.639, \rho=0.361, \varepsilon_{t} \sim N(0,1), R=1.01, p^{*}=100$, Var $=1, c=0.2$, $g=0.5, \kappa^{F}=0.001, \kappa^{M}=0.003, T=1000, N=1000$. 
Table 8: Normalized Profits

\begin{tabular}{cccc}
\hline & Informed Traders & Male & Female \\
\hline Male:Female 50:50 & & & \\
Mean & 0.190 & -0.196 & -0.186 \\
SD & 1.553 & 1.628 & 1.512 \\
Skewness & 1.000 & -1.183 & -0.885 \\
\hline Male:Female 95:5 & & & \\
Mean & 0.171 & -0.172 & -0.159 \\
SD & 1.574 & 1.585 & 1.462 \\
Skewness & 1.153 & -1.178 & -0.855 \\
\hline
\end{tabular}

Note: Results for market with $50 \%$ informed traders to $50 \%$ positive feedback traders with AR(1) dividend process. Male:Female is the proportion of male traders to female traders within the group of positive feedback traders. Normalized profits are volume weighted profits per period. Each simulation was a run for 1000 time steps. Profits are averaged over 1000 runs. All values are significantly different at $99 \%$ confidence level. Parameters: $b=0.639, \rho=0.361, \varepsilon_{t} \sim N(0,1), R=1.01, p^{*}=100, \operatorname{Var}=1, c=0.2, g=0.5, \kappa^{F}=0.001$, $\kappa^{M}=0.003, T=1000, N=1000$.

Table 9: Profits -Positive Outcomes

\begin{tabular}{ccc}
\hline & \multicolumn{2}{c}{ Normalized Profits } \\
\cline { 2 - 3 } & Male & Female \\
\hline Male:Female 50:50 & \\
Mean & 0.824 & 0.822 \\
SD & 1.106 & 1.011 \\
Skewness & 3.008 & 2.536 \\
Outperforming & $42 \%$ & $58 \%$ \\
Positive return periods & 460 & 460 \\
\hline Male:Female 95:5 & & \\
Mean & 0.806 & 0.802 \\
SD & 1.089 & 0.992 \\
Skewness & 3.056 & 2.567 \\
Outperforming & $42 \%$ & $58 \%$ \\
Positive return periods & 465 & 465 \\
\hline
\end{tabular}

Note: Results for market with $50 \%$ informed traders to $50 \%$ positive feedback traders with AR(1) dividend process. Profits analyzed here are positive profits generated by male positive feedback traders and female positive feedback traders. Normalized profits are volume weighted profits per period. Male:Female is the proportion of male traders to female traders within the group of positive feedback traders. Outperforming is the fraction of periods that the given gender outperforms the other gender. Each simulation was a run for 1000 time steps. Profits are averaged over 1000 runs. All values are significantly different at $99 \%$ confidence level. Parameters: $b=0.639, \rho=0.361, \varepsilon_{t} \sim N(0,1), R=1.01, p^{*}=100, \operatorname{Var}=1, c=0.2, g=0.5$, $\kappa^{F}=0.001, \kappa^{M}=0.003, T=1000, N=1000$. 
Table 10: Moments of Asset Prices

\begin{tabular}{ccccccc}
\hline & \multicolumn{2}{c}{ Male:Female $50: 50$} & & \multicolumn{3}{c}{ Male:Female $95: 5$} \\
\cline { 2 - 3 } \cline { 5 - 6 } & Value & SD & & Value & SD \\
\hline Term & & & & & \\
Volatility & 1.741 & $(0.263)$ & & 1.703 & $(0.267)$ \\
Skewness & 0.180 & $(0.841)$ & & 0.167 & $(0.912)$ \\
Kurtosis & -0.475 & $(2.048)$ & & -0.437 & $(2.454)$ \\
\hline
\end{tabular}

Note: Results for market with 50\% informed traders to $50 \%$ positive feedback traders with two-state Ornstein-Uhlenbeck dividend process. Male:Female is the proportion of male traders to female traders within the group of positive feedback traders. Each simulation was a run for 1000 time steps. Market statistics are averaged over 1000 runs, standard deviations across runs in parenthesis. All values are significantly different at $99 \%$ confidence level. Parameters: $\lambda^{\text {high }}=1, \lambda^{\text {low }}=1.3, \mu^{\text {high }}=1.0576, \mu^{\text {low }}=0.95, \alpha=0.99$, $\sigma=1, \Delta t=1, \varepsilon_{t} \sim N(0,1), R=1.01, p^{*}=100$, Var $=1, c=0.2, g=0.5, \kappa^{F}=0.001, \kappa^{M}=0.003$, $T=1000, N=1000$.

Table 11: Moments of Asset Prices

\begin{tabular}{cccccc}
\hline & \multicolumn{2}{c}{ Informed:Positive Feedback $50: 50$} & & \multicolumn{2}{l}{ Informed:Positive Feedback $70: 30$} \\
\cline { 2 - 3 } \cline { 5 - 6 } & Value & SD & & Value & SD \\
\hline Term & & & & 1.645 & $(0.274)$ \\
Volatility & 1.703 & $(0.267)$ & & 0.147 & $(1.058)$ \\
Skewness & 0.167 & $(0.912)$ & & & \\
\hline
\end{tabular}

Note: Results for market with $95 \%$ to $5 \%$ female traders within the group of positive feedback traders with two-state Ornstein-Uhlenbeck dividend process. Informed:Positive Feedback is the proportion of informed traders to positive feedback traders in the market. Each simulation was a run for 1000 time steps. Market statistics are averaged over 1000 runs, standard deviations across runs in parenthesis. All values are significantly different at $99 \%$ confidence level. Parameters: $\lambda^{\text {high }}=1, \lambda^{\text {low }}=1.3, \mu^{\text {high }}=1.0576, \mu^{\text {low }}=0.95$, $\alpha=0.99, \sigma=1, \Delta t=1, \varepsilon_{t} \sim N(0,1), R=1.01, p^{*}=100, \operatorname{Var}=1, c=0.2, g=0.5, \kappa^{F}=0.001$, $\kappa^{M}=0.003, T=1000, N=1000$. 
Table 12: Normalized Profits

\begin{tabular}{cccc}
\hline & Informed Traders & Male & Female \\
\hline Male:Female 50:50 & & & \\
Mean & 0.212 & -0.219 & -0.207 \\
SD & 1.802 & 1.890 & 1.755 \\
Skewness & 1.188 & -1.378 & -1.069 \\
\hline Male:Female 95:5 & & & \\
Mean & 0.190 & -0.191 & -0.177 \\
SD & 1.828 & 1.841 & 1.698 \\
Skewness & 1.346 & -1.372 & -1.040 \\
\hline
\end{tabular}

Note: Results for market with $50 \%$ informed traders to $50 \%$ positive feedback traders with two-state Ornstein-Uhlenbeck dividend process. Male:Female is the proportion of male traders to female traders within the group of positive feedback traders. Normalized profits are volume weighted profits per period. Each simulation was a run for 1000 time steps. Profits are averaged over 1000 runs. All values are significantly different at $99 \%$ confidence level. Parameters: $\lambda^{\text {high }}=1, \lambda^{\text {low }}=1.3, \mu^{\text {high }}=1.0576, \mu^{\text {low }}=0.95$, $\alpha=0.99, \sigma=1, \Delta t=1, \varepsilon_{t} \sim N(0,1), R=1.01, p^{*}=100, \operatorname{Var}=1, c=0.2, g=0.5, \kappa^{F}=0.001$, $\kappa^{M}=0.003, T=1000, N=1000$.

Table 13: Profits -Positive Outcomes

\begin{tabular}{ccc}
\hline & \multicolumn{2}{c}{ Normalized Profits } \\
\cline { 2 - 3 } & Male & Female \\
\hline Male:Female 50:50 & \\
Mean & 0.920 & 0.916 \\
SD & 1.308 & 1.200 \\
Skewness & 3.450 & 3.006 \\
Outperforming & $42 \%$ & $58 \%$ \\
Positive return periods & 460 & 460 \\
\hline Male:Female 95:5 & & \\
Mean & 0.899 & 0.894 \\
SD & 1.288 & 1.178 \\
Skewness & 3.494 & 3.038 \\
Outperforming & $41 \%$ & $59 \%$ \\
Positive return periods & 466 & 466 \\
\hline
\end{tabular}

Note: Results for market with $50 \%$ informed traders to $50 \%$ positive feedback traders with two-state Ornstein-Uhlenbeck dividend process. Profits analyzed here are positive profits generated by male positive feedback traders and female positive feedback traders. Normalized profits are volume weighted profits per period. Male:Female is the proportion of male traders to female traders within the group of positive feedback traders. Outperforming is the fraction of periods that the given gender outperforms the other gender. Each simulation was a run for 1000 time steps. Profits are averaged over 1000 runs. All values are significantly different at $99 \%$ confidence level. Parameters: $\lambda^{\text {high }}=1, \lambda^{\text {low }}=1.3, \mu^{\text {high }}=1.0576$, $\mu^{\text {low }}=0.95, \alpha=0.99, \sigma=1, \Delta t=1, \varepsilon_{t} \sim N(0,1), R=1.01, p^{*}=100, \operatorname{Var}=1, c=0.2, g=0.5$, $\kappa^{F}=0.001, \kappa^{M}=0.003, T=1000, N=1000$. 
Table 14: Moments of Asset Prices

\begin{tabular}{ccccccc}
\hline & \multicolumn{2}{c}{ Male:Female $50: 50$} & & \multicolumn{2}{c}{ Male:Female $95: 5$} \\
\cline { 2 - 3 } \cline { 5 - 6 } & \multicolumn{2}{c}{ Value } & SD & & Value & SD \\
\hline Term & & & & & \\
Volatility & 9.768 & $(1.570)$ & & 9.700 & $(1.567)$ \\
Skewness & 0.082 & $(1.397)$ & & 0.080 & $(1.420)$ \\
Kurtosis & 0.109 & $(11.524)$ & & 0.148 & $(12.478)$ \\
\hline
\end{tabular}

Note: Results for market with $50 \%$ informed traders to $50 \%$ positive feedback traders with two-state Ornstein-Uhlenbeck dividend process. Male:Female is the proportion of male traders to female traders within the group of positive feedback traders. Each simulation was a run for 1000 time steps. Market statistics are averaged over 1000 runs, standard deviations across runs in parenthesis. All values are significantly different at $99 \%$ confidence level. Parameters: $\lambda^{\text {high }}=1, \lambda^{\text {low }}=1.3, \mu^{\text {high }}=1.3452, \mu^{\text {low }}=0.7, \alpha=0.99$, $\sigma=1, \Delta t=1, \varepsilon_{t} \sim N(0,1), R=1.01, p^{*}=100, \operatorname{Var}=1, c=0.2, g=0.5, \kappa^{F}=0.001, \kappa^{M}=0.003$, $T=1000, N=1000$.

Table 15: Moments of Asset Prices

\begin{tabular}{cccccc}
\hline & \multicolumn{2}{c}{ Informed:Positive Feedback $50: 50$} & & \multicolumn{2}{l}{ Informed:Positive Feedback $70: 30$} \\
\cline { 2 - 3 } Term & Value & SD & & Value & SD \\
Volatility & 9.700 & $(1.567)$ & & 9.582 & $(1.563)$ \\
Skewness & 0.080 & $(1.420)$ & & 0.079 & $(1.460)$ \\
\hline
\end{tabular}

Note: Results for market with $95 \%$ to $5 \%$ female traders within the group of positive feedback traders with two-state Ornstein-Uhlenbeck dividend process. Informed:Positive Feedback is the proportion of informed traders to positive feedback traders in the market. Each simulation was a run for 1000 time steps. Market statistics are averaged over 1000 runs, standard deviations across runs in parenthesis. All values are significantly different at $99 \%$ confidence level. Parameters: $\lambda^{\text {high }}=1, \lambda^{\text {low }}=1.3, \mu^{\text {high }}=1.3452, \mu^{\text {low }}=0.7$, $\alpha=0.99, \sigma=1, \Delta t=1, \varepsilon_{t} \sim N(0,1), R=1.01, p^{*}=100$, Var $=1, c=0.2, g=0.5, \kappa^{F}=0.001$, $\kappa^{M}=0.003, T=1000, N=1000$. 
Table 16: Normalized Profits

\begin{tabular}{cccc}
\hline & Informed Traders & Male & Female \\
\hline Male:Female 50:50 & & & \\
Mean & 0.361 & -0.374 & -0.352 \\
SD & 4.412 & 4.579 & 4.315 \\
Skewness & 9.696 & -9.790 & -9.624 \\
\hline Male:Female 95:5 & & & \\
Mean & 0.322 & -0.323 & -0.298 \\
SD & 4.419 & 4.440 & 4.165 \\
Skewness & 9.801 & -9.808 & -9.667 \\
\hline
\end{tabular}

Note: Results for market with 50\% informed traders to $50 \%$ positive feedback traders with two-state Ornstein-Uhlenbeck dividend process. Male:Female is the proportion of male traders to female traders within the group of positive feedback traders. Normalized profits are volume weighted profits per period. Each simulation was a run for 1000 time steps. Profits are averaged over 1000 runs. All values are significantly different at $99 \%$ confidence level. Parameters: $\lambda^{\text {high }}=1, \lambda^{\text {low }}=1.3, \mu^{\text {high }}=1.3452, \mu^{\text {low }}=0.7$, $\alpha=0.99, \sigma=1, \Delta t=1, \varepsilon_{t} \sim N(0,1), R=1.01, p^{*}=100$, Var $=1, c=0.2, g=0.5, \kappa^{F}=0.001$, $\kappa^{M}=0.003, T=1000, N=1000$.

Table 17: Profits -Positive Outcomes

\begin{tabular}{ccc}
\hline & \multicolumn{2}{c}{ Normalized Profits } \\
\cline { 2 - 3 } & Male & Female \\
\hline Male:Female 50:50 & 0.978 & 0.979 \\
Mean & 1.995 & 1.900 \\
SD & 6.918 & 6.780 \\
Skewness & $41 \%$ & $59 \%$ \\
Outperforming & 480 & 480 \\
Positive return periods & & \\
Male:Female 95:5 & 0.965 & 0.966 \\
Mean & 1.966 & 1.871 \\
SD & 6.857 & 6.686 \\
Skewness & $41 \%$ & $59 \%$ \\
Outperforming & 487 & 487 \\
Positive return periods & & \\
\hline
\end{tabular}

Note: Results for market with $50 \%$ informed traders to $50 \%$ positive feedback traders with two-state Ornstein-Uhlenbeck dividend process. Profits analyzed here are positive profits generated by male positive feedback traders and female positive feedback traders. Normalized profits are volume weighted profits per period. Male:Female is the proportion of male traders to female traders within the group of positive feedback traders. Outperforming is the fraction of periods that the given gender outperforms the other gender. Each simulation was a run for 1000 time steps. Profits are averaged over 1000 runs. All values are significantly different at $99 \%$ confidence level. Parameters: $\lambda^{\text {high }}=1, \lambda^{\text {low }}=1.3, \mu^{\text {high }}=1.3452$, $\mu^{\text {low }}=0.7, \alpha=0.99, \sigma=1, \Delta t=1, \varepsilon_{t} \sim N(0,1), R=1.01, p^{*}=100$, Var $=1, c=0.2, g=0.5$, $\kappa^{F}=0.001, \kappa^{M}=0.003, T=1000, N=1000$. 


\section{References}

Adams, T. (2011): "Testosterone and high finance do not mix: so bring on the women," The Guardian, Available at, http://www.theguardian.com/world/2011/jun/ 19/neuroeconomics--women--city--financial--crash.

Allen, H., AND M. P. TAylor (1990): "Charts, noise and fundamentals in the London foreign exchange market," Economic Journal, 100(400), 49-59.

Apicella, C. L., A. Dreber, B. Campbell, P. B. Gray, M. Hoffman, and A. C. LitTLE (2008): "Testosterone and financial risk preferences.," Evolution and Human Behavior, 29(6), 384-390.

Apicella, C. L., A. Dreber, And J. Mollerstrom (2014): "Salivary testosterone change following monetary wins and losses predicts future financial risk-taking," Psychoneuroendocrinology, 39, 58-64.

ARCHER, J. (1991): "The influence of testosterone on human aggression," British Journal of Psychology, 82, 337-343.

(2006): "Testosterone and human aggression: an evaluation of the challenge hypothesis," Neuroscience and Behavioral Reviews, 30, 319-345.

Barber, B. M., And T. Odean (2001): "Boys will be boys: gender, overconfidence, and common stock investment," The Quaterly Journal of Economics, 116(1), 261-292.

Belsky, G. (2012): "Why we need more female traders on Wall Street," Time, Available at, http://business.time.com/2012/05/15/ why--we--need--more--female--traders--on--wall--street/

Bhamra, H. S., And R. UpPal (2014): "Asset prices with heterogeneity in preferences and beliefs," Review of Financial Studies, 27(2), 519-580. 
Book, A. S., K. B. Starzyk, and V. L. Quinsey (2001): "The relationship between testosterone and aggression: a meta-analysis," Aggression and Violent Behavior, 6, 579599.

Bos, P. A., D. Terburg, and J. Van Honk (2010): "Testosterone decreases trust in socially naive humans," PNAS, 107(22), 9991-9995.

Brock, W. A., and C. H. Hommes (1998): "Heterogeneous beliefs and routes to chaos in a simple asset pricing model," Journal of Economic Dynamics and Control, 22(8-9), $1235-1274$.

Brooks, J. H., AND J. R. REDdon (1996): "Serum testosterone in violent and nonviolent young offenders," Journal of Clinical Psychology, 52(4), 475-483.

Buser, T. (2011): "Hormones and social preferences," Tinbergen Institute Discussion Paper, 11-046/3.

Campbell, J. Y., and A. S. Kyle (1993): "Smart money, noise trading, and stock price behavior," Review of Economic Studies, 60(1), 1-34.

Chabakauri, G. (2013): "Dynamic equilibrium with two stocks, heterogeneous investors, and portfolio constraints," Review of Financial Studies, 26(12), 3104-3141.

Coates, J. M. (2012): "The hour between dog and wolf," Penguin Group.

Coates, J. M., M. Gurnell, and Z. Sarnyai (2010): "From molecule to market: steroid hormones and financial risk-taking," Phil. Trans. R. Soc. B, 365, 331-343.

Coates, J. M., and J. Herbert (2008): "Endogenous steroids and financial risk taking on a London trading floor," Proceedings of the National Academy of Sciences, 105(16), $6167-6172$.

Coates, J. M., And L. Page (2009): "A note on trader Sharpe ratios," PLoS ONE, 4(11), e8036. 
Cronqvist, H., A. Previtero, S. Siegel, and R. E. White (2015): "The fetal origins hypothesis in finance: prenatal environment, the gender gap, and investor behavior," Review of Financial Studies, Available at, https://rfs.oxfordjournals.org/content/ early/2015/12/03/rfs.hhv065.full.

Cueva, C., R. E. Roberts, T. Spencer, N. Rani, M. Tempest, P. N. Tobler, J. Herbert, and A. Rustichini (2015): "Cortisol and testosterone increase financial risk taking and may destabilize markets," Scientific Reports, Available at, http://www. nature.com/articles/srep11206.

Dabbs, J. M. J., R. L. Frady, T. S. Carr, and N. F. Besch (1987): "Saliva testosterone and criminal violence in young adult prison inmates," Psychosomatic Medicine, 49, $174-182$.

Dabbs, J. M. J., and M. F. Hargrove (1997): "Age, testosterone, and behavior among female prison inmates," Psychosomatic Medicine, 59(5), 477-480.

De Long, J. B., A. Shleifer, L. H. Summers, and R. J. Waldmann (1990a): "Noise trader risk in financial markets," Journal of Political Economy, 98(4), 703-738.

(1990b): "Positive feedback investment strategies and destabilizing rational speculation," Journal of Finance, 45(2), 379-395.

Dreber, A., And M. Hoffman (2007): "Risk preferences are partially predetermined," Mimeo.

_ (2010): "Biological basis of sex difference in risk aversion and competitiveness," Mimeo.

Eckel, C. C., And S. C. Fullbrunn (2015): "Thar SHE Blows? Gender, Competition, and Bubbles in Experimental Asset Markets," American Economic Review, 105(2), 906920. 
FAmA, E. F. (1965): "The behavior of stock-market prices," Journal of Business, 38(1), $34-105$.

Foroohar, R. (2013): "Sorry, Paul Tudor Jones: Its Male Not Female Traders We Should Be Worried About," Time, Available at, http://business.time.com/2013/05/24/ sorry--paul--tudor--jones--its--male--not--female--traders--we--should-be--worried--about/.

Friedman, M. (1953): "The case for flexible exchange rates. In: Essays in Positive Economics," University of Chicago Press, Chicago, IL.

Frye, C. A., M. E. Rhodes, R. Rosellini, and B. Svare (2002): "The nucleus accumbens as a site of action for rewarding properties of testosterone and its 5alphareduced metabolites," Pharmacology Biochemistry and Behavior, 74(1), 119-127.

Garbarino, E., R. Slonim, and J. Sydnor (2011): "Digit ratios (2D:4D) as predictors of risky decision making," Journal of Risk and Uncertanity, 42, 1-26.

Guo, M., And H. OU-YANG (2015): "Feedback trading between fundamental and nonfundamental information," Review of Financial Studies, 28(1), 247-296.

Hoffmann, A. O., And H. Shefrin (2014): "Technical Analysis and Individual Investors," Journal of Economic Behavior and Organization, 107, 487-511.

Kahneman, D., And A. TVersky (1982): "Intuitive prediction: Biases and corrective procedures. In Judgment under uncertainty: Heuristics and biases," Cambridge University Press.

Kivilighan, K. T., D. A. Granger, and A. Booth (2005): "Gender difference in testosterone and cortisol response to competition," Psychoneuroendocrinology, 30, 58-71.

Kogan, L., S. A. Ross, J. Wang, and M. M. Westerfield (2006): "The price impact and survival of irrational traders," Journal of Finance, 61(1), 195-229. 
Kyle, A. S. (1985): "Countinuous auctions and insider trading," Econometrica, 53(6), $1315-1335$.

Lagarde, C. (2013): "Dare the difference," Finance and Development, 50(2), 22-23.

LESLIE, I. (2012): "Too much testosterone, too much confidence: the psychology of banking," The Guardian, Available at, http://www.theguardian.com/business/2012/jun/ 30/banking--psychology--testosterone--confidence--sex.

Lewellen, W. G., R. C. Lease, and G. G. Schlarbaum (1980): "Portfolio design and portfolio performance: the individual investor," Working Paper 86, National Bureau of Economic Research.

Longstaff, F. A., And J. Wang (2012): "Asset pricing and the credit market," Review of Financial Studies, 25(11), 3169-3215.

LuCAS, R. E. (1972): "Econometric testing of the natural rate hypothesis. In: The Econometrics of Price Determination Conference," Board of Governors of the Federal Reserve System and Social Science Research Council, pp. 50-59.

Maras, A., M. Laucht, D. Gerdes, C. Wilhelm, S. Lewicka, D. HaAck, L. MalISOva, And M. H. Schmidt (2003): "Association of testosterone and dihydrotestosterone with externalizing behavior in adolescent boys and girls," Psychoneuroendocrinology, 28(7), 932-940.

Mazur, A., And A. Booth (1998): "Testosterone and dominance in men," Behavioral and Brain Sciences, 21, 353-397.

Menkhoff, L., And M. P. TAYlor (2007): "The obstinate passion of foreign exchange professionals: Technical analysis," Journal of Economic Literature, 45(4), 936-972.

Muth, J. F. (1961): "Rational expectations and the theory of price movements," Econometrica, 29, 315-335. 
Roberti, J. W. (2004): "A review of behavioral and biological correlates of sensation seeking," Journal of Research in Personality, 38, 256-279.

Roney, J. R., S. V. Mahler, and D. Maestripieri (2003): "Behavioral and hormonal responses of men to brief interactions with women," Evolution and Human Behavior, 24, $365-375$.

Rowe, R., B. Maughan, C. M. Worthman, E. J. Costello, and A. Angold (2004): "Testosterone, antisocial behavior and social dominance in boys," Biological Psychiatry, $55(5), 546-552$.

SAACKE, P. (2002): "Technical analysis and the effectiveness of central bank intervention," Journal of International Money and Finance, 21, 459-479.

Sapienza, P., L. Zingales, and D. Maestripieri (2009): "Gender differences in financial risk aversion and career choices are affected by testosterone," Proceedings of the National Academy of Sciences of the United States of America, 106(36), 15268-15273.

Schultheiss, O. C., And W. Rohde (2002): “Implicit power motivation predicts men's testosterone changes and implicit learning in a contest situation," Hormones and Behavior, 41, 195-202.

Schultheiss, O. C., M. M. Wirth, C. M. Torges, J. S. Pang, M. A. Villacorta, AND K. M. WELSH (2005): “Effects of implicit power motivation on men's and women's implicit learning and testosterone changes after social victory or defeat," Journal of Personality and Social Psychology, 88(1), 174-188.

Spiegel, M., and A. Subrahmanyam (1992): "Informed speculation and hedging in a noncompetitive securities market," Review of Financial Studies, 5, 307-330.

Taylor, M. P., And H. Allen (1992): "The use of technical analysis in the foreign exchange market," Journal of International Money and Finance, 11(3), 304-314. 
Trainor, B. C., I. M. Bird, And C. A. Marler (2004): "Opposing hormonal mechanisms of aggression revealed through short-lived testosterone manipulations and multiple winning experiences," Hormones and Behavior, 45, 115-121.

Van Honk, J., D. J. L. G. Schutter, E. J. Hermans, P. Putman, A. Tuiten, and H. KoppeschaAR (2004): "Testosterone shifts the balance between sensitivity for punishment and reward in healthy young women," Psychoneuroendocrinology, 29(7), 937943.

VAyAnos, D. (2001): "Strategic trading in a dynamic noisy market," Journal of Finance, $56,131-171$.

Vermeersch, H., G. T'Sjoen, J.-M. Kaufman, and J. Vincke (2008): "The role of testosterone in aggressive and non-aggressive risk-taking in adolescent boys," Hormones and Behavior, 53, 463-471. 